\title{
Bus Rapid Transit and Economic Development: Case Study of the Eugene-Springfield BRT System
}

\author{
Arthur C. Nelson, Bruce Appleyard, Shyam Kannan, Reid Ewing, \\ Matt Miller, Dejan Eskic \\ Metropolitan Research Center, University of Utah
}

\begin{abstract}
Bus rapid transit (BRT) in the United States is relatively recent. BRT has many promises, one of which is enhancing the economic development prospects of firms locating along the route. Another is to improve overall metropolitan economic performance. In this article, we evaluate this issue with respect to one of the nation's newest BRT systems that operates in a metropolitan area without rail transit: Eugene-Springfield, Oregon. While the metropolitan area lost jobs between 2004 and 2010, jobs grew within 0.25 miles of BRT stations. Using shift-share analysis, we find that BRT stations are attractive to jobs in several economic sectors. Planning and policy implications are offered along with an outline for future research.
\end{abstract}

\section{Introduction}

In this article, we assess the relationship between bus rapid transit (BRT) and the change in share of jobs in an urban area during the 2000s. Eugene-Springfield, Oregon, is our case study. The Eugene-Springfield BRT system is well-suited for this analysis because it has one of the nation's newest BRT systems, so we can assess economic influences in the short-term; its system is reasonably representative of emerging BRT design; and we were able to acquire employment data, allowing us conduct spatially-related analysis. Our analysis covers the years 2004 and 2010, 
which were three years before and after the BRT system was opened. Our article includes these sections: Fixed-Guideway Transit Systems and Economic Development; Overview of the Eugene-Springfield BRT System; Research Method and Data; Assessment of Results; and Planning and Policy Implications.

\section{Fixed-Guideway Transit Systems and Economic Development}

Bus rapid transit is a specialized form of fixed-guideway transit systems that include heavy or "fifth" rail, such as the New York subway; light rail, such as provided in Charlotte and San Diego; non-tourist-related streetcar, such as seen in Portland and New Orleans; and bus rapid transit, such as the new Eugene-Springfield service operated by the Lane Transit District, known as the Emerald Express or EmX. Fixed-guideway systems reinvent the idea of agglomeration economies, which is a cornerstone of urban economic development. In this section, we review the role of agglomeration economies in economic development, assess how the advantages of agglomeration economies are undermined by automobile dependency, and summarize the role of fixed-guideway transit systems in recreating those economies.

Cities are formed and grow in large part by creating agglomeration economies (Glaeser 2011). Annas, Arnott, and Small (1998) define the term as "the decline in average cost as more production occurs within a specified geographical area" ( $p$. 1427). They arise specific to certain economic sectors, however. As more firms in a related sector cluster together, costs of production fall as productivity increases. These economies can spill over into complementary sectors (Holmes 1999). Cities can become ever larger as economies of agglomeration are exploited (Ciccone and Hall 1996). If cities get too large, however, congestion occurs, which leads to diseconomies of scale. The result may be relocation of firms, but this can weaken economies of scale (Bogart 1998). Highways connecting the city to outlying areas can induce firms to relocate, thereby reducing agglomeration diseconomies of scale through sacrificing some economies, though overall economic improvement is debatable (Boarnet 1997). Cities thus spread out, and although the urban area may contain more people and jobs, the advantages of agglomeration economies are weakened.

One way to preserve agglomeration economies and reduce diseconomies is to improve transportation systems; this is a role of fixed-guideway transit systems. Within about 0.25 to 0.50 miles from transit stations accessing these systems, firms maximize the benefits of agglomeration economies (Cervero et al. 2004). Moreover, some firms can also benefit from expanded access to the labor force residing 
within walking distance of transit stations, wherever they are located (Belzer, Srivastava, and Austin 2011).

There is another aspect of agglomeration economies identified by Chapman and Noland (2011). Although transit systems can lead to higher-density development by shifting new jobs and population to station areas, it could lead, instead, to the redistribution of existing development even in the absence of growth.

In part because of their role in facilitating agglomeration economies, there is a growing body of research showing that rail-based public transit enhances economic development (see Nelson et al. 2009). These economies are facilitated when they improve accessibility between people and their destinations (Litman 2009) by reducing travel time and the risk of failing to arrive at a destination (Weisbrod and Reno 2009). At the metropolitan scale, adding transit modes in built-up urban areas increases aggregate economic activity (Graham 2007).

Economic development can be measured in many ways. One is by evaluating how the market responds to the presence of transportation investments, such as rail stations. Higher values closer to stations implies market capitalization of economic benefits, which can occur only when economic activity increases. Only a few studies have shown this with respect to commercial property values (Nelson 1999) and none for BRT, although one study shows positive residential property value effects (see Perk and Catalá 2009).

Our focus here is whether and the extent to which there is a link between a specific form of transit-BRT-and job growth. We know from recent work that not all firms benefit from transit. In their recent study of employment within one-half mile of transit stations serving 34 rail systems, Belzer, Srivastava and Austin (2011) found that while jobs increase in the Arts/Entertainment/Recreation sectors, as well as the Accommodation and Food Services and Health Care and Social Assistance sectors, they fell in the Manufacturing sector. They also found that the Public Administration sector had the greatest share of jobs found near transit stations. Several other sectors also concentrated around transit stations, such as Professional, Scientific, and Technical Services and Retail. On the other hand, as a whole, the station areas experienced declining shares of jobs relative to their regions, with the exception of jobs in the Utilities, Information, and Arts/Entertainment/ Recreation sectors. Belzer, Srivastava, and Austin (2011) surmised that much of the metropolitan job growth continues to favor auto-oriented locations. Their study did not report results for individual systems and, as it was based on data through 2008, came just one year after the Eugene-Springfield BRT opened. 
There is no research directly linking BRT to economic development, however. Our case study of the EmX system lays the groundwork for determining whether there is a link and, if so, which economic sectors are affected. We also investigate whether distance from BRT stations makes a difference. Literature indicates that economic benefits occur within one-half mile of transit stations, but studies have focused principally on rail systems. Whether BRT has similarly large spatial areas of attractiveness is not known.

\section{Overview of the Eugene-Springfield BRT System}

Planning for the Emerald Express (EmX BRT) began in 1996, when local officials and citizens assessed transit alternatives. Unlike many smaller to medium-size metropolitan areas, Eugene-Springfield is constrained from outward urban expansion by an urban growth boundary (see Nelson and Dawkins 2004). A principle objective of urban containment is to use transit to provide more efficient connections within urbanized areas than automobiles. The planning process managed by the Lane Transit District considered light rail and bus rapid transit options. In 2001, the BRT option was selected over light rail because it was the best option for service and price, especially given the area's modest population size (about 300,000 residents and 140,000 jobs in the metropolitan area'). Moreover, analysis indicates that the BRT option significantly enhances transit service and achieves many of the benefits of light rail but without the cost.

Construction of the BRT system started in 2004 and EmX service began in 2007. The first EmX route connects downtown Eugene with Springfield, Oregon (Thole, Cain, and Flynn 2009). The EmX includes dedicated bus lanes for about 60 percent of the route. This includes lanes separated by curbs or clearly demarcated travel lanes. EmX vehicles share the road with traffic elsewhere. Vehicles are also provided signal priority, including special signaling at intersections. The BRT vehicles are custom-built with doors on both sides that provide for loading from platforms on either side. In 2008, the first full year of operation, EmX carried 1.5 million riders. ${ }^{2}$

The system is expanding away from the route connecting downtown Eugene and Springfield westward along commercial corridors. In 2011, the Gateway extension opened. It added 7.8 miles to the EmX running north-south on Pioneer Parkway from the Springfield Station to the Gateway Mall and the Sacred Heart Medical Center. On the other hand, efforts by the Lane Transit District to expand the EmX to the west on 11th Avenue are met with opposition from business owners who fear it would disrupt customer traffic. 


\section{Research Method and Data}

We evaluate the EmX BRT system for its economic development outcomes in terms of employment change within 0.25 and 0.50 miles of BRT stations. To do this, our method is twofold. First, we perform a descriptive analysis of the extent to which the EmX BRT may affect the concentration of new employment within those distance bands around BRT stations. Second, we use shift-share analysis to assess particular patterns of firm location within those distance bands relative to the Eugene-Springfield metropolitan area as a whole to identify those economic sectors that may especially benefit from BRT proximity, and those that do not.

Our experimental interest is whether job changes in the metropolitan area are associated with the BRT route and stations. Our overall research design uses the case study method based on post-hoc outcomes; that is, because we know where the jobs are located throughout the study area, we can test for the shift in share of jobs before the introduction of the BRT in 2007, with outcomes later.

Our employment data come from the Local Employment Dynamics (LED) database. LED data are assembled by the Census Bureau through a voluntary partnership among 45 states. The data provide details about jobs, workers, and the structure of local economies. The LED uses existing data from state-supplied administrative records on workers and employers and is integrated with existing censuses, surveys, and other administrative records.

LED data have been made available annually since 2002 at the Census block level. Blocks can be aggregated into higher-level geographic units for analysis for any given year or set of years. Jobs are reported at the two-digit level of the North American Industrial Classification System (NAICS). For our study, the LED data are collected for Lane County as a whole to analyze employment change between 2004-three years before the EmX began operating — and 2010 — three years after operations commenced. The year 2004 was also four years before the Great Recession when the metropolitan area (comprising Lane County) had 139,000 jobs then. In 2010, a year after the Great Recession had passed officially, the metropolitan area had 136,000 jobs. Thus, not only are we able to determine whether and the extent to which EmX influenced employment location patterns but also whether those patterns may have been affected by the economic downturn. Using Census blocks, employment sheds are constructed at 0.25 and 0.50 mile distances around BRT stations. If the BRT system has no effect on job location, we would see no difference in the share of jobs near BRT stations before (2004) or after (2010) system commencement with the added benefit of testing for outcomes with respect to the Great Recession. 


\section{Assessment of Results}

Table 1 reports our overall assessment of change in employment between 2004 and 2010. We report jobs for areas within 0.25 miles of a station, between 0.25 and 0.50 miles of a station, and the balance of the metropolitan area. Overall, for the metropolitan area outside the 0.50 mile BRT station areas, jobs fell by about 5 percent or more than 5,000 . Jobs stayed about the same between 0.25 and 0.50 miles of station areas but increased by about 10 percent or nearly 3,000 within 0.25 miles of station areas.

For the most part, changes in jobs follow similar patterns at three levels of geography, but there are interesting exceptions. Within 0.25 miles of BRT stations, jobs in the Information, Real Estate, Management, Administrative, Education, Health Care, Lodging/Food, and other sectors all increased by more than 10 percent, with Management more than doubling. In contrast, between 0.25 and 0.50 miles from stations, many of those same sectors lost jobs (Information, Professional, Management, and Administrative), while others grew in both distance-bands (Real Estate, Finance, Education, and Health Care). Jobs in the Transportation and Arts/Entertainment/Recreation sector increased substantially between 0.25 and 0.50 miles of BRT stations (160\% and 130\%, respectively). Retail gained slightly in both distance bands but fell for the balance of the metropolitan area. A surprise based on other research is that jobs within 0.25 miles of a BRT station fell in the Arts/Entertainment/Recreation sector and fell slightly in the Public Administration sector; on the other hand, those sectors gained jobs between 0.25 and 0.50 miles of BRT stations. Also surprising is that the balance of the metropolitan area did far better in gaining jobs in Health Care, Lodging/Food, and Public Administration than station areas.

We surmise that the market is sorting jobs based on competition for BRT proximity. It may be that office uses are able to outbid Arts/Entertainment/Recreation for locations closest to BRT stations (the sector lost nearly 120 jobs within 0.25 miles) but many of those displaced jobs still located within 0.50 miles of BRT stations (the sector gained 46 jobs between 0.25 and 0.50 miles).

We cannot say conclusively that there is a cause-and-effect relationship between BRT locations and increasing concentration of certain kinds of jobs within 0.5 miles of BRT stations; this will be the subject of future research. 


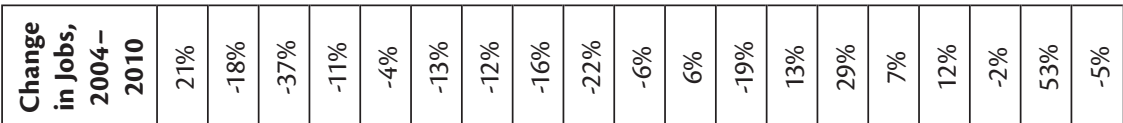

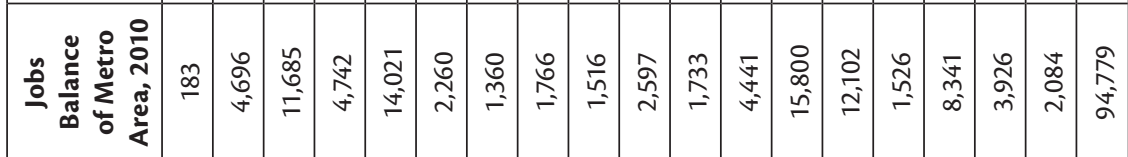

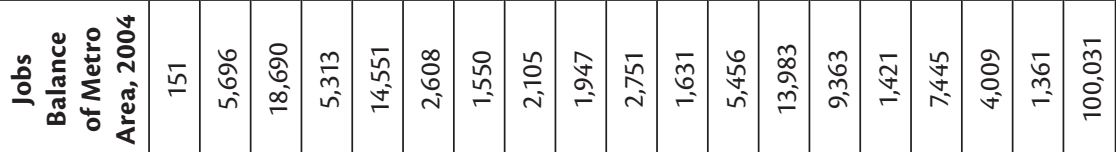
产

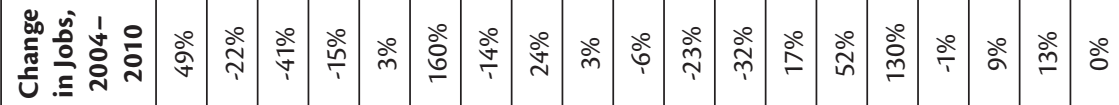
융 웅

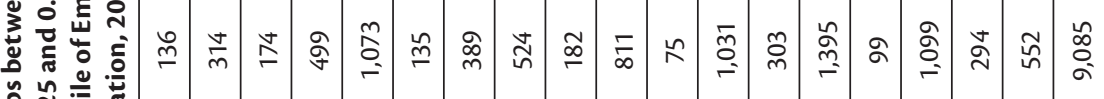

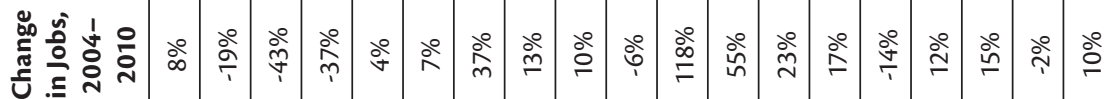

늘 흘

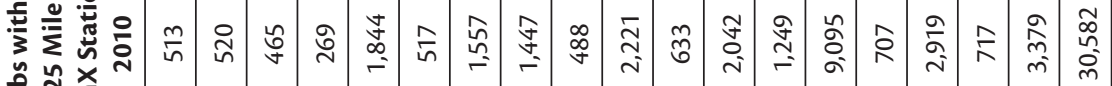

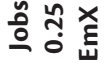

응

$\Xi$

돌

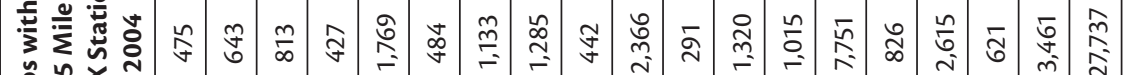
ํㅡ를

돈

तั

\begin{tabular}{|c|c|c|c|c|c|c|c|c|c|c|c|c|c|c|c|c|c|c|c|}
\hline 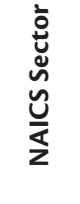 & 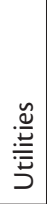 & 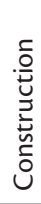 & 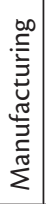 & $\begin{array}{l}\frac{0}{J} \\
\frac{\tilde{U}}{0} \\
\frac{1}{3}\end{array}$ & $\begin{array}{l}\overline{\overline{\widetilde{J}}} \\
\widetilde{\mathscr{~}}\end{array}$ & 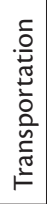 & 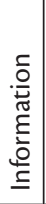 & 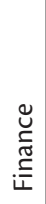 & 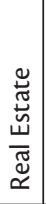 & 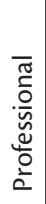 & 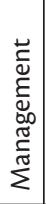 & 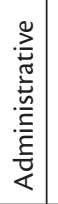 & 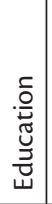 & 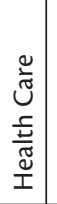 & 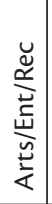 & 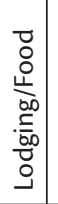 & 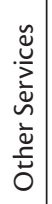 & 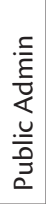 & \begin{tabular}{|l}
$\overline{0}$ \\
$\stackrel{0}{0}$
\end{tabular} \\
\hline$\frac{\tilde{U}}{\Sigma} \frac{0}{0}$ & $\approx$ & $\stackrel{\eta}{\sim}$ & $\frac{m}{m}$ & $\stackrel{\sim}{\sim}$ & $\begin{array}{l}u \\
y \\
I \\
v \\
v\end{array}$ & $\begin{array}{l}\stackrel{\Im}{\mathrm{J}} \\
\mathbf{1} \\
\infty \\
\dot{v}\end{array}$ & $\bar{n}$ & $\tilde{N}$ & $\hat{n}$ & in & in & $\stackrel{n}{n}$ & $\bar{\sigma}$ & $\widetilde{\sigma}$ & $\kappa$ & $\approx$ & $\bar{\infty}$ & $\sigma$ & \\
\hline
\end{tabular}


Also, this does not necessarily mean that BRT proximity confers a comparative advantage for selected economic sectors. For this, we turn to shift-share analysis. In particular, because we know where the jobs were located throughout the study area in 2004 and 2010, we can compare shifts in share of jobs before and after the introduction of the EmX.

Shift/share analysis is used to decompose employment changes in local areas. The analysis identifies industries that have a comparative advantage in the local area. In our case, we use the Eugene-Springfield metropolitan area's non-farming, forestry, fishing, or mining jobs and apply shift-share analysis to determine the nature of employment change with respect to being with 0.25 miles and between 0.25 and 0.50 miles of BRT stations in 2004 and 2010.

Shift-share analysis assigns the change or shift in the share or concentration of jobs with respect to the region, other economic sectors, and the local area. The "region" can be any level of geography and is often the nation or the state. In our case, where we want to see whether there are intra-metropolitan shifts in the share of jobs by sector, our region is the metropolitan area itself. The "local" area is often a city or county or even state, but it can be any geographic unit that is smaller than the region. Our local areas are the station areas within 0.25 miles and between 0.25 and 0.50 miles of the nearest BRT station; we call this the BRT Station Area. As shifts in the share of jobs may vary by sector over time because of changes in economic sector mixes (there are now more high-tech jobs in the Eugene-Springfield metropolitan area than jobs in forestry), there is also an "industry mix" adjustment that we call the Sector Mix. Using notations by the Carnegie Mellon Center for Economic Development (no date), the shift-share formula is:

$$
\mathrm{SS}_{\mathrm{i}}=M \mathrm{~A}_{\mathrm{i}}+\mathrm{SM}_{\mathrm{i}}+\mathrm{BRT}_{\mathrm{i}}
$$

Where,

$\mathrm{SS}_{\mathrm{i}}=$ Shift-Share

$M A_{i}=$ Metropolitan Area share

$\mathrm{SM}_{\mathrm{i}}=$ Sector Mix

$B R T_{i}=B R T$ Station Area shift

The Metropolitan Area (MA) share measures by how much total employment in a BRT station area changed because of change in the metropolitan area economy during the period of analysis. If metropolitan area employment grew by 10 percent 
during the analysis period, then employment in the BRT station area would have also grown by 10 percent if there is no BRT effect. The Sector Mix (SM) identifies fast-growing or slow-growing economic sectors in a BRT station area based on the metropolitan area growth rates for the individual economic sectors. For instance, a BRT station area with an above-average share of the metropolitan area's highgrowth sectors would have grown faster than a BRT station area with a high share of low-growth sectors. The BRT station area shift, also called the "competitive effect," is the most relevant component; it identifies a BRT station area's leading and lagging sectors. The competitive effect compares a BRT station area's growth rate in a given economic sector with the growth rate for that same sector at the metropolitan area. A leading sector is one where that sector's BRT station area growth rate is greater than its metropolitan area growth rate. A lagging sector is one where the sector's BRT station area growth rate is less than its metropolitan area growth rate. ${ }^{3}$

The equations for each component of the shift-share analysis are:

$$
\begin{aligned}
M A= & \left({ }_{B} B R T \text { station area }{ }^{t-1} \cdot M A^{t} / M A^{t-1}\right) \\
S M= & {\left[\left({ }_{i} B R T \text { station area }{ }^{t-1} \cdot{ }_{i} M A t /{ }_{i} M A^{t-1}\right)-M A\right] } \\
B R T= & {\left[{ } _ { i } B R T \text { station areat } { } ^ { t - 1 } \cdot \left({ }_{i} B R T \text { station area }{ }^{t} /{ }_{i} B R T \text { station } \text { area }^{t-1}-{ }_{i} M A^{t} /\right.\right.} \\
& \left.\left.{ }_{i} A^{t-1}\right)\right]
\end{aligned}
$$

Where:

${ }_{i} B R T$ station area ${ }^{t-1}=$ number of jobs in the BRT station area sector (i) at the beginning of the analysis period $(t-1)$

${ }_{i B R T}$ station area ${ }^{\mathrm{t}}=$ number of jobs in the BRT station area in sector (i) at the end of the analysis period $(t)$

$M A^{t-1}=$ total number of jobs in the metropolitan area at the beginning of the analysis period $(\mathrm{t}-1)$

$M A^{t}=$ total number of jobs in the metropolitan area at the end of the analysis period $(\mathrm{t})$

${ }_{i} M A^{t-1}=$ number of jobs in the metropolitan area in sector (i) at the beginning of the analysis period $(t-1)$

${ }_{i} M A^{t}=$ number of jobs in the metropolitan area in sector (i) at the end of the analysis period $(\mathrm{t})$ 
Table 2 reports only the BRT station area shift results for the areas within 0.25 miles, between 0.25 and 0.50 miles, and within 0.50 miles of BRT stations. Figure 1 illustrates the BRT share for all the first two station area distances $(0.25$ and between 0.25 and 0.50 miles). The stacked bars in this figure allow us to see the individual and combined effects of distance from BRT stations by economic sector.

Table 2. Shift-Share of Analysis of Job Change with Respect to Distance from BRT Stations, 2004 and 2010

\begin{tabular}{|l|c|c|c|}
\hline \multicolumn{1}{|c|}{ NAICS Sector } & $\begin{array}{c}\text { BRT Shift } \\
\mathbf{0 . 2 5} \text { Mile }\end{array}$ & $\begin{array}{c}\text { BRT Shift } \\
\mathbf{0 . 2 5}-\mathbf{0 . 5 0} \text { Mile }\end{array}$ & $\begin{array}{c}\text { BRT Shift } \\
\mathbf{0 . 5 0} \text { Mile }\end{array}$ \\
\hline Utilities & $(38)$ & 30 & $(8)$ \\
\hline Construction & $(8)$ & $(14)$ & $(22)$ \\
\hline Manufacturing & $(41)$ & $(8)$ & $(50)$ \\
\hline Wholesale Trade & $(103)$ & $(10)$ & $(113)$ \\
\hline Retail Trade & 118 & 59 & 177 \\
\hline Transportation and Warehousing & 69 & 87 & 156 \\
\hline Information & 361 & $(86)$ & 276 \\
\hline Finance and Insurance & 187 & 110 & 298 \\
\hline Real Estate and Rental \& Leasing & 111 & 31 & 143 \\
\hline Professional, Scientific, and Technical Services & $(7)$ & 0 & $(7)$ \\
\hline Management of Companies and Enterprises & 281 & $(43)$ & 238 \\
\hline Administrative/Support/Waste Management/ & 846 & $(341)$ & 504 \\
\hline Remediation Svcs & 95 & 10 & 104 \\
\hline Educational Services & $(615)$ & 242 & $(373)$ \\
\hline Health Care and Social Assistance & $(134)$ & 55 & $(79)$ \\
\hline Arts/Entertainment/Recreation & 26 & $(132)$ & $(106)$ \\
\hline Accommodation and Food Services & 91 & 23 & 114 \\
\hline Other Services (except Public Administration) & $(542)$ & $(1)$ & $(543)$ \\
\hline Public Administration & 698 & 12 & 710 \\
\hline Total & & & \\
\hline
\end{tabular}

Source: Data from Local Employment Dynamics. 


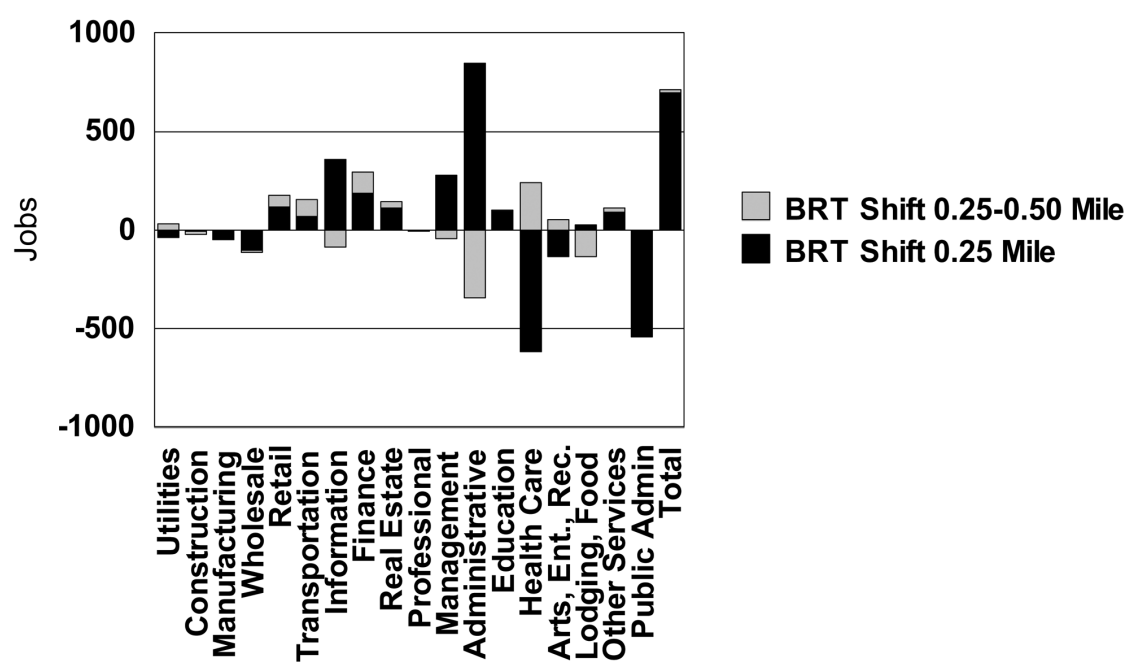

Figure 1. Shift-share distribution of employment change with respect to BRT station areas, Eugene-Springfield metropolitan area, 2004-2010

We use Figure 1 in combination with Table 2 to identify economic sectors that seem especially attracted to, or even repelled by, BRT stations. We also offer insights for individual economic sectors and how they relate to broader findings reported by Belzer, Srivastava and Austin (2011).

A number of sectors appear to be displaced by other sectors seeking BRT station proximity, particularly Construction, Manufacturing, and Wholesale Trade. This is consistent with findings of Belzer, Srivastava, and Austin (2011). Jobs in the Utilities sector appear to be displaced with 0.25 miles of BRT stations, but they seem to have shifted to areas between 0.25 and 0.50 miles.

A number of other sectors appear to be attracted to BRT station areas as a whole, although especially within 0.25 miles of a station. These include Retail Trade, Transportation and Warehousing, Finance and Insurance, Real Estate and Rental \& Leasing, and other services. This is also consistent with findings of Belzer, Srivastava, and Austin (2011).

An interesting finding is that certain sectors are attracted to the closest BRT locations but considerably less so up to 0.50 miles, and, in some cases, jobs are shifted away from the $0.25-0.50$ mile band but into the closer band. For instance, the 0.25-0.50 mile band saw a negative shift in Information, Management of Companies and Enterprises, Administrative/Support/Waste Management/Remediation 
Services, and Accommodation and Food Service. In many instances, the positive shift into the 0.25 mile band was greater than the negative shift out of the $0.25-$ 0.50 mile band. While these are sectors that Belzer, Srivastava, and Austin (2011) expect to be attracted to station areas generally, the fact that their positive shift is so large toward the closer band suggests that, at least for BRT, the location advantage may not reach out as far as for rail modes.

There is also the reverse situation in which there is a negative shift in the closest band but a positive one in the $0.25-0.50$ mile band. This is the case with Health Care and Social Assistance in which the shift away from the closer band was the largest of all shifts, while the shift to the $0.25-0.50$ mile band was the largest there. Part of this may be explained by a major medical facility that opened in the late 2000s outside the BRT station areas.

Then there is the interesting case of Public Administration, which had the second largest shift away from the closest distance band and there does not appear to any offsetting shift in the $0.25-0.50$ band. The explanation is likely severe local government budget cuts during the late 2000s that resulted in hundreds of jobs being cut that were near BRT stations.

There are two other observations. First, of the combined shift in jobs toward BRT station areas of 710 jobs, only 12 are in the $0.25-0.50$ distance band. Thus, essentially, the entire overall shift in jobs favoring BRT station areas occurred within 0.25 miles of them. Second, the BRT system may have a resiliency effect. Where the Eugene-Springfield metropolitan area as a whole lost jobs between 2004 and 2010, jobs were actually added within 0.25 miles of BRTs stations.

\section{Planning and Policy Implications}

We are impressed to see how the Eugene-Springfield market responded so quickly to the EmX BRT system. Future research in other metropolitan areas and over longer periods of time in Eugene-Springfield can confirm whether our results are robust. Success, however, is likely due to several factors that need to be considered in planning, designing, and implementing BRT systems. In our view, the key planning lessons include the following: ${ }^{4}$

1. The success of projects is due, in part, to a high level of cooperation among public agencies, non-profit development communities, and private developers. 
2. In cities where the real estate market is not already strong, an active transit agency with a TOD program and/or active community development organization is critical.

3. Real estate developers and owners view permanence as an important factor for building around a BRT system. A key advantage of rail is that once the investment has been made, the real estate industry can usually rely on its permanence over the many decades it takes to maximize profits from highdensity investments at or near those stations. However, even in the cities with a relatively low level of infrastructure, BRT may be viewed as permanent when there is a clear long-term commitment by the transit agency. In the case of EmX, this commitment includes substantial capital investment in providing separated lanes for exclusive BRT use and light-rail-like transit stations.

4. The transit corridor must be amenable to high-density development, so the route needs to assure this opportunity. Corridors placed in areas without major employment or housing destinations are not likely to attract development, regardless of mode.

5. Providing financial incentives for TODs at BRT stations does not appear to be as important for attracting developer interest. Developers are much more interested in an expedited permitting or rezoning process, as time is a critical factor in making development projects financially viable.

One implication is that BRT may provide for many more opportunities for smaller metropolitan areas to serve numerous job sectors. We note that an urbanized population of about one million appears to be the smallest capable of supporting light rail, with Salt Lake City being an example. Light-rail-like benefits may be achieved only in smaller metropolitan areas through BRT. Moreover, within metropolitan areas that have light or heavy rail, costs may prohibit their expansion. BRT could be the next-generation solution to increase multimodal options. In either case, the BRT results for Eugene-Springfield's EmX may provide metropolitan planning organizations with a rationale for investing in BRT for economic development reasons, especially in situations where rail does not "pencil."

We hope our work stimulates more research in this area. In the case of EugeneSpringfield, we find that the job growth occurred near BRT stations over a short period of time where otherwise the metropolitan area lost jobs as a whole. Further research is needed to determine cause-and-effect relationships between BRT stations and employment change, whether there is variation among economic sectors, whether employment shifts occur in the short term as well as the long term, 
and the extent to which local economic benefits improve with respect to BRT, among others. There is also the question of whether and to what extent BRT affects residential location patterns.

It would also be important to know whether BRT technologies have different economic development and residential location outcomes. Most light rail systems, for instance, use the same system design and mechanical technologies. In contrast, BRT systems can vary widely based on rail, station/platform, carriage, signalization, and other features. Success with EmX's BRT flavor may not be replicated with other BRT flavors.

We hope this article serves as a starting point for advancing discussion on BRT as a viable economic development tool.

\section{Endnotes}

${ }^{1}$ Compiled from http://www.Itd.org/search/showresult.html?versionthread $=45 a 4 b 8$ $3927 f b a 5 c b 751 c 741 b f 4 a c 81 e 3$.

${ }^{2}$ For a brief history, see $h t t p: / / w w w . I t d . o r g / s e a r c h / s h o w r e s u l t . h t m /$ versionthread= aac1492116416eb1c13546ffe5d14e6b.

${ }^{3}$ We have adapted the Carnegie Mellon Center for Economic Development's description of how shift-share works for our application.

${ }^{4}$ We are informed in the discussion by Breakthrough Technologies Institute (2008), Bus Rapid Transit and Transit Oriented Development: Case Studies on Transit Oriented Development Around Bus Rapid Transit Systems in North America and Australia, Washington, DC. http://www.crcog.org/publications/TransportationDocs/ NBHBusway/2010/BRT-TOD-Report.pdf.

\section{Acknowledgments}

The authors acknowledge that support for research leading to this article was provided by the U.S. Department of Housing and Urban Development through its Sustainable Communities program and the National Institute for Transportation and Communities. 


\section{References}

Anas, A., R. Arnott, and K. A. Small. 1998. Urban spatial structure. Journal of Economic Literature 36(3): 1426-1464.

Belzer, Dena, Sujata Srivastava, and Mason Austin. 2011. Transit and Regional Economic Development. Oakland, CA: Center for Transit-Oriented Development.

Boarnet, Marlon. 1997. Highways and economic productivity: Interpreting recent evidence. Journal of Planning Literature 11(4): 476-486.

Bogart, William T. (1998). The Economics of Cities and Suburbs. Upper Saddle River, NJ: Prentice Hall.

Carnegie Mellon Center for Economic Development. Undated. Methods of regional analysis: Shift-share. Pittsburgh, PA: H. John Heinz School of Public Policy and Management, Carnegie Mellon University. Accessed from http:// www.andrew.cmu.edu/user/jp87/URED/readings/Shift_Share.pdf.

Cervero, R., S. Murphy, C. Ferrell, N. Goguts, Y. Tsai, G. B. Arrington, J. Boroski, J. Smith-Heimer, R. Golem, P. Peninger, E. Nakajima, E. Chui, R. Dunphy, M. Myers, S. McKay, and N. Witsenstein. 2004. Transit-Oriented Development in the United States: Experiences, Challenges, and Prospects. Washington, DC: Transportation Research Board.

Ciccone, Antonio, and Robert E. Hall. 1996. Productivity and the density of economic activity. American Economic Review 86: 54-70.

Diaz, R. B., M. Chang, G. Darido, M. Chang, E. Kim, D. Schneck, M. Hardy, J. Bunch, M. Baltes, D. Hinebaugh, L. Wnuk, F. Silver, and S. Zimmerman. 2004. Characteristics of Bus Rapid Transit for Decision-Making. Washington, DC: Federal Transit Administration, U.S. Department of Transportation.

Glaeser, Edward. 2011. Triumph of the City How Our Greatest Invention Makes Us Richer, Smarter, Greener, Healthier, and Happier. New York: Penguin Books.

Graham, D. J. 2007. Agglomeration, productivity and transport investment. Journal of Transport Economics and Policy (JTEP) 41(3), September: 317-343. www. ingentaconnect.com/content/lse/jtep/2007/00000041/00000003/art00003. Summarized in OECD/ITF Discussion Paper 2007-11, www.internationaltransportforum.org/jtrc/DiscussionPapers/DiscussionPaper11.pdf. 
Holmes, Thomas. 1999. How industries migrate when agglomeration economies are important. Journal of Urban Economics 45: 240-263.

Levinson, H., S. Zimmerman, J. Clinger, S. Rutherford, R. Smith, J. Cracknell, and R. Soberman. 2003. Bus Rapid Transit Volume 1: Case Studies in Bus Rapid Transit. Washington, DC: Transportation Research Board.

Litman, T. 2009. Evaluating Transportation Economic Development Impacts. Victoria, BC: Victoria Transportation Institute, http://www.vtpi.org/econ_dev.pdf.

Nelson, A. C., and C. J. Dawkins. 2004. Urban Containment in the United States. American Planning Association (Chicago).

Nelson, A. C., G. Anderson, R. Ewing, P. Perlich, T. W. Sanchez, and K. Bartholomew. 2009. The Best Stimulus for the Money: Briefing Papers on the Economics of Transportation Spending. Metropolitan Research Center at the University of Utah for Smart Growth America. http://www.smartgrowthamerica.org/documents/thebeststimulus.pdf.

Nelson, A. C. 1999. Transit stations and commercial property values. Journal of Public Transportation 2(3): 77-96.

Perk, V. A., and M. Catalá. 2009. Land use impacts of bus rapid transit: Effects of BRT station proximity on property values along the Pittsburgh Martin Luther King, Jr. East Busway. Federal Transit Administration, Washington, D.C. http://www. nbrti.org/docs/pdf/Property\%20Value\%20Impacts\%20of\%20BRT_NBRTI.pdf

Tann, H. M., and D. Hinebaugh. 2009. Characteristics of Bus Rapid Transit for Decision-Making. Washington, D.C.: Federal Transit Administration, U.S. Department of Transportation.

Thole, C., A. Cain, and J. Flynn. 2009. The EMX Franklin Corridor BRT project evaluation. Washington, DC: Federal Transit Administration, U.S. Department of Transportation.

Weisbrod, G., and A. Reno. 2009. Economic impact of public transportation investment. American Public Transportation Association (www.apta.com). www. apta.com/resources/reportsandpublications/Documents/economic_impact_ of_public_transportation_investment.pdf; additional information at www. edrgroup.com/library/public-transport/rail/econimpact-public-transporttcrp-j-11-17.html. 


\section{About the Authors}

ARthur C. Nelson (ACNelson@MetropolitanResearchCenter.org) is Presidential Professor of City \& Metropolitan Planning, Executive Director of the Metropolitan Research Center, and Director of the Master of Real Estate Development Program at the University of Utah. His research areas include economic development, public finance, transportation and land use analysis, and metropolitan development patterns.

BRUCE APPLeYARD (bappleyard@cfaconsultants.com) is a Principal of the planning, research and urban design firm CFA Consultants. He has more than 20 years of experience on the intersection between transportation, land use, urban design, and environmental quality in support of a diverse range of sustainability and livability objectives.

Shyam KANNAN (E014284@wmata.com) is the Washington Metropolitan Area Transportation Authority's assistant general manager for planning and joint development. Previously, he was a principal and director of RCLCO's economic development practice.

Reid Ewing (ewing@arch.utah.edu) is a Professor of City \& Metropolitan Planning at the University of Utah, coordinator of the planning doctoral program, and a bi-monthly columnist on planning research at Planning magazine. His research interests are research itself, land use and transportation planning, smart growth, and public health.

MAtT M. Miller is a Graduate Research Assistant at the Metropolitan Research Center and a doctoral student in the City and Metropolitan Planning Program at the University of Utah. His research interests are transit-oriented development, urban redevelopment, and urban form.

DejAn EsKIC (dejan.eskic@utah.edu) is a Research Analyst at the University of Utah's Metropolitan Research Center. He holds a degree in Urban Planning with a focus on Regional Planning. His research interests are smart growth, economic and real estate development, transportation and land use relationships, and fiscal analysis. 